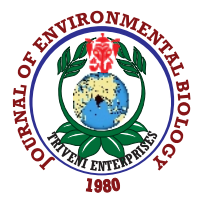

\title{
Effects of UV-B pre-treatments on physiological properties and accumulation of active ingredients in herbal plant, Prunella vulgaris
}

\author{
H. Tang', J. Yang', X.R. Zhang ', L.P. Cao', Q. Qin', M. Zhao', C. Li' and Y.H. Chen ${ }^{1 *}$ \\ ${ }^{1}$ College of Pharmaceutical Sciences, Chengdu Medical College, Chengdu-610500, P.R. China \\ ${ }^{2}$ Traditional Chinese Medicine Co., LTD., Shanghai-200 002, P.R. China \\ *Corresponding Author Email: chenyuhang221@126.com
}

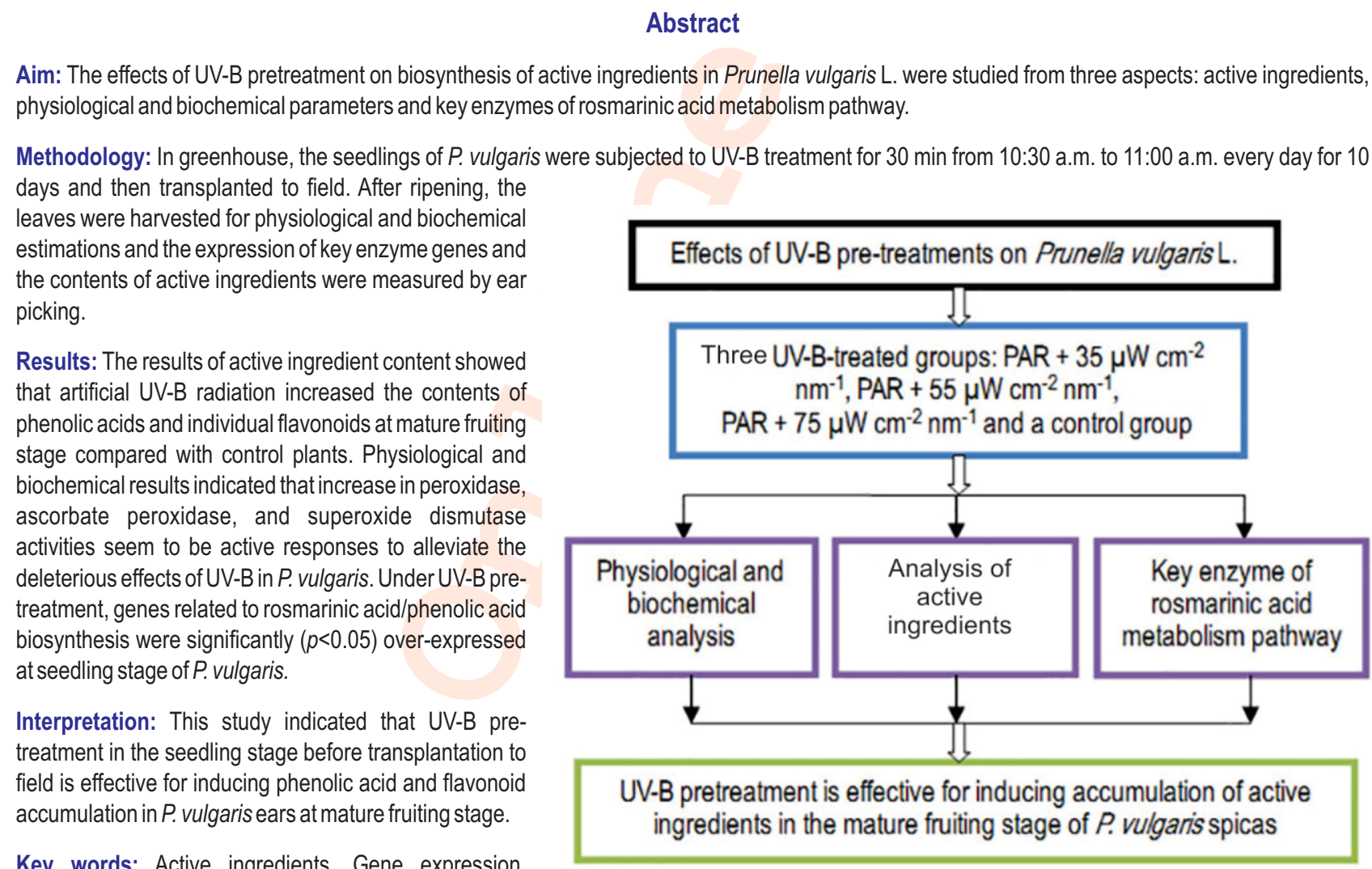
Prunella vulgaris L., Ultraviolet-B

How to cite : Tang, H., J. Yang, X.R. Zhang, L.P. Cao, Q. Qin, M. Zhao, C. Li and Y.H. Chen: Effects of UV-B pre-treatments on physiological properties and accumulation of active ingredients in herbal plant, Prunella vulgaris. J. Environ. Biol., 41, 556-562 (2020). 


\section{Introduction}

A loss of ozone layer is resulting in depletion of stratosphere and increase in the penetration of ultraviolet-B (UV$B, 280-320 \mathrm{~nm}$ ) radiation through Earth's surface, with potentially harmful consequences for natural plant ecosystems and agricultural production (Caldwell et al., 2003). Ultraviolet (UV-B) radiation is a key abiotic stress factor with many indirect and direct effects on plants (Singh et al., 2011; Eichholz et al., 2012). Increasing UV-B radiation has shown both favourable and unfavourable effects on the growth and physiology of plants (Liu et al., 2013; Zhang et al., 2017). Generally, increased UV-B radiation is considered harmful to plants (Agrawal and Mishra, 2009; Tossi et al., 2011). Numerous studies have shown that UV$B$ radiation adversely affects plants, often leading to the production of reactive oxygen species (ROS) (Barta et al., 2004). Some medicinal plants activate various defence mechanisms to resist oxidative stress, including increases in antioxidant enzymes (Yan et al., 2016), production of antioxidant secondary metabolites (mainly phenolic acids and flavonoids) and expression of key enzyme-encoding genes in the phenylpropanoid biosynthetic pathway (Zhang and Bjorn, 2009; Dolzhenko et al., 2010). It is likely that these antioxidant defence mechanisms scavenge ROS to counter the deleterious effects of UV-B radiation.

Prunella vulgaris L. (Family: Labiatae) is a perennial plant that is widely distributed in Europe, North-east Asia and North America (Chen et al., 2018). The aerial parts and dried spicas are used to treat pulmonary tuberculosis, thyroid gland malfunction, infectious hepatitis and mastitis (Bai et al., 2016). In addition to its pharmaceutical industrial use, the fresh leaves of $P$. vulgaris at seedling stage are used as food in China (Chen et al., 2019). $P$. vulgaris dry spicas and fresh leaves contain large amounts of antioxidants and nutritional components, such as flavonoids, phenolics, triterpenes and polysaccharides (Cheung and Zhang, 2008; Wang et al., 2011), which are considered to present potential medicinal and health food functions. Previous studies have reported that abiotic stresses such as drought, different soil nutrient concentrations, and different light spectra significantly enhance the contents of active ingredients (phenolic compounds and flavonoids) in P. vulgaris plants (Chen et al., 2013; Fazal et al., 2016). It has been assumed that UV-B pre-treatment of $P$. vulgaris at seedling stage in green house may induce greater ROS production, leading to higher active ingredient content in the plants after transfer to field. On the other hand, it is not completely understood whether synthesis of secondary metabolites is determined by transient metabolic regulation or involves changes in gene expression in the phenylpropanoid synthetic pathway.

Keeping in view the above, the present study was carried out to investigate the effects of UV-B pre-treatment on the antioxidative defence system, oxidative stress markers, phenylpropanoid biosynthetic pathway gene expression, and active ingredient biosynthesis in P. vulgaris plants. This study will contribute to revealing whether UV-B pre-treatment is a potential stressor for $P$. vulgaris seedlings grown in the greenhouse following transfer to field conditions for production of more active ingredients.

\section{Materials and Methods}

Plant material: The experiment was carried out at Chengdu Medical College Botanic Garden, Chengdu, PR. China. Seeds of P. vulgaris were collected in June 2017 and disinfected with $9 \%$ $\mathrm{H}_{2} \mathrm{O}_{2}$ for approximately $30 \mathrm{~min}$, then rinsed several times with tap water. On 20 March 2018, twenty seeds were sown in plastic pots with $900 \mathrm{~g}$ of nutrient soil, and each pot contained 3 seedlings. All pots were placed in the experimental greenhouse under $14.6 \pm 13.08$ kilolux of photosynthetically active radiation (PAR), $50-70 \%$ relative humidity, and temperatures of $25^{\circ} \mathrm{C} / 12^{\circ} \mathrm{C}$ (day/night). Plant growth was observed daily and the plants were watered as and when required.

UV-B irradiation: On 1 April 2018 seedlings of $P$. vulgaris were divided into four groups: three UV-B-treated groups (lower dose: $\mathrm{PAR}+35 \mu \mathrm{W} \mathrm{cm}{ }^{-2} \mathrm{~nm}^{-1}$; intermediate dose: PAR + $55 \mu \mathrm{W} \mathrm{cm} \mathrm{nm}^{-1}$; higher dose: PAR $+75 \mu \mathrm{W} \mathrm{cm} \mathrm{nm}^{-1}$ ) and a control group (CK). Each group was replicated three times, and each replicate consisted of 24 plants. The PAR and light intensities of UV-B were $25000 \pm 100$ lux and $700 \pm 20 \mu \mathrm{W} \mathrm{cm} \mathrm{nm}^{-1}$ under natural conditions, respectively. UV-B radiation were applied using a portable illuminometer (UV-340A, Lutron, Taiwan) and UV-B fluorescent tubes (Beijing Electric Light Source Research Institute, $40 \mathrm{~W}$, China) for enhanced UV-B radiation. P. vulgaris in seedling stage was subjected to UV-B treatment for 30 min every day from 10:30 a.m. to 11:00 a.m. for 10 days. After 10 days of treatment, the control plants and one group of UV-B-treated plants were collected for physiological and biochemical analyses. Another three groups of treated plants and control plants were transferred to field conditions. $P$. vulgaris spicas were harvested at mature fruiting stage to analyse the influence of UV-B pretreatment on active ingredient biosynthesis.

Anthocyanin and UV-B-absorber contents: Anthocyanin was estimated by the method of Chen et al. (2019). Chopped fresh leaves $(0.5 \mathrm{~g})$ were soaked in dark with $5 \mathrm{ml}$ of acidified methanol and shaken 4-5 times for $72 \mathrm{hr}$. UV absorber and anthocyanin contents were estimated by recording the absorbance at 280 and $530 \mathrm{~nm}$, separately. The results were expressed in Units $\mathrm{g}^{-1} \mathrm{f}$.wt. The procedure was repeated three times for each treatment.

Antioxidant enzymes activities: Antioxidant enzymes activities were estimated similar as described by Chen et al., 2019. Briefly, fresh leaves $(0.5 \mathrm{~g})$ were placed in $4.5 \mathrm{ml}$ of phosphate buffer $\left(0.1 \mathrm{~mol} \mathrm{l}^{-1}, \mathrm{pH} 7.43\right)$ solution, ground to a powder in ultra-low temperature liquid nitrogen, and centrifuged at $4^{\circ} \mathrm{C}$ for complete extraction. Determination of peroxidase (POD) activity by absorbance change at $420 \mathrm{~nm}$. Catalase (CAT) and superoxide dismutase (SOD) activities were measured at $405 \mathrm{~nm}$ and $550 \mathrm{~nm}$, respectively. The results of measuring ascorbate peroxidase (APX) activity at $290 \mathrm{~nm}$ were expressed in units of $\mathrm{mg} \mathrm{prot}^{-1}$, and the glutathione (GSH) 
content measured at $420 \mathrm{~nm}$ was calculated as milligrams of glutathione per gram of protein.

Sugar and soluble protein, malondialdehyde (MDA), proline and hydrogen peroxide $\left(\mathrm{H}_{2} \mathrm{O}_{2}\right)$ contents: The measurement methods for these compounds were as described by Chen et al., 2019. Briefly, the sample $(0.5 \mathrm{~g})$ was homogenized with phosphate-buffered saline (PBS) and centrifuged, and the supernatant was determined according to the assay kits (Nanjing Jiancheng Bioengineering Institute, Nanjing, China). Sugar and soluble protein, proline, MDA and $\mathrm{H}_{2} \mathrm{O}_{2}$ contents were measured at $595 \mathrm{~nm}, 620 \mathrm{~nm}, 520 \mathrm{~nm}, 532 \mathrm{~nm}$ and $405 \mathrm{~nm}$, respectively.

Estimation of secondary metabolite: Spicas were collected at mature fruiting stage from two-month-old plants grown under natural conditions. Spicas were dried at $60 \pm 2^{\circ} \mathrm{C}$ for $4 \mathrm{hr}$. The extraction and HPLC analysis methods for active ingredient compounds (caffeic acid, salviaflaside, rosmarinic acid, hyperoside, oleanolic acid and ursolic acid) were performed as described by Chen et al. (2019)..

RNA extraction and RT-PCR analysis: Mixed leaf samples were stored in at $-80^{\circ} \mathrm{C}$ in liquid nitrogen, and TRIZOL reagent (Invitrogen, Carlsbad, CA, USA) was used to extract total mRNA. Approximately, $100 \mathrm{ng}$ of mRNA was employed for cDNA synthesis using PrimerScript RT kit (TaKaRa Biotechnology (Dalian) Co. Ltd). cDNA was used for RT-PCR, and the primers used are shown in Table 5. RT-PCR was performed in a Piko Real-Time PCR System (PIKORed 96, Thermo Fisher, USA) using the SYBR Premix Ex Taq II kit (TaKaRa Biotechnology (Dalian) Co. Ltd). PCR procedure was as follows: $95^{\circ} \mathrm{C}$ for $30 \mathrm{sec}$, followed by $95^{\circ} \mathrm{C}$ for $5 \mathrm{sec}, 55^{\circ} \mathrm{C}$ for $30 \mathrm{sec}, 72^{\circ} \mathrm{C}$ for 30 sec for 40 cycles. $\beta$-actin (Kim et al. 2014) was used as an internal standard (not affected by UV-B), and the 2- $\Delta \Delta C T$ method was used to calculate relative expression levels.

Statistical analyses: The data are expressed as the means \pm SDs. SPSS 21.0 software (SPSS, Chicago, IL, USA) was used to determine the one-way analysis of variance (ANOVA).

\section{Results and Discussion}

Anthocyanin and UV-B-absorber contents were determined in $P$. vulgaris under UV-B radiation (Table 1).
Anthocyanin content increased due to UV-B radiation, however, the difference was not significant. The levels of UV absorber was also in significantly different between the treated and control groups. The activities of SOD, POD, APX and GSH content showed increasing trends under UV-B radiation as; compared to un-irradiated treatment. APX, POD and GSH showed significant $(p<0.05)$ increase. SOD activities in untreated and treated plants with lower or higher UV-B levels were slightly increased but showed insignificant $(p<0.05)$ difference compared with control plants. CAT activity of plants under UV-B radiation was significantly reduced compared to un-irradiated plants (Table 2).

The soluble protein, $\mathrm{H}_{2} \mathrm{O}_{2}$ and MDA contents were found to increase under UV-B radiation. Compared with un-irradiated treatment, MDA content was found to increase significantly $(p<0.05)$, however, soluble proteins showed slight insignificant increase. The perusal of data revealed that the levels of $\mathrm{H}_{2} \mathrm{O}_{2}$ increased significantly $(p<0.05)$ in high UV-B radiation group; however, $\mathrm{H}_{2} \mathrm{O}_{2}$ levels under lower and intermediate UV-B irradiation showed slight reduction or enhancement with insignificant $(p<0.05)$ difference as compared to un-irradiated plants. The contents of soluble sugars significantly $(p<0.05)$ increased to a peak value under intermediate UV-B radiation but were slightly decreased under lower UV-B treatment and significantly $(p<0.05)$ decreased under higher UV-B treatment. Lower UV-B radiation enhanced the proline content, but intermediate and higher UV-B radiation significantly $(p<0.05)$ reduced the proline content (Table 3).

Under pre-treatment with UV-B radiation, the contents of caffeic acid, rosmarinic acid, hyperoside and salviaflaside showed an increasing trend, which was significantly $(p<0.05)$

Table 1: Effect of UV-B pre-treatment for 10 days on anthocyanin and UV absorber contents in $P$. vulgaris leaves at seedling stage

\begin{tabular}{lll}
\hline Treatments & Anthocyanin & UV absorber \\
\hline Control & $3.01 \pm 0.07^{\mathrm{a}}$ & $2.77 \pm 0.00^{\mathrm{a}}$ \\
$35 \mu \mathrm{W} \mathrm{cm} \mathrm{nm}^{-1}$ & $3.07 \pm 0.06^{\mathrm{a}}$ & $2.77 \pm 0.00^{\mathrm{a}}$ \\
$55 \mu \mathrm{W} \mathrm{cm} \mathrm{nm}^{-1}$ & $3.12 \pm 0.07^{\mathrm{a}}$ & $2.77 \pm 0.00^{\mathrm{a}}$ \\
$75 \mu \mathrm{W} \mathrm{cm} \mathrm{nm}^{-1}$ & $3.12 \pm 0.02^{\mathrm{a}}$ & $2.76 \pm 0.00^{\mathrm{a}}$ \\
\hline
\end{tabular}

Values are mean of three replicates \pm S.D. The same letter a in each column indicate insignificant difference at $p<0.05$

Table 2: Effect of UV-B pre-treatment for 10 days on SOD, POD, CAT and APX activities and GSH content at seedling stage in P. vulgaris leaves

\begin{tabular}{|c|c|c|c|c|c|}
\hline Treatments & $\begin{array}{l}\text { POD activity } \\
\text { (U mg } \text { m protein) }^{-1}\end{array}$ & $\begin{array}{l}\text { CAT activity } \\
\text { (U mg } \text { m protein) }^{-1}\end{array}$ & $\begin{array}{l}\text { SOD activity } \\
\text { (U } \mathrm{mg}^{-1} \text { protein) }\end{array}$ & $\begin{array}{l}\text { APX activity } \\
\text { (U mg } \text { m protein) }^{-1}\end{array}$ & $\begin{array}{l}\text { GSH content } \\
\text { (mg GSH g }{ }^{-1} \text { protein) }\end{array}$ \\
\hline$\overline{\mathrm{CK}}$ & $3.62 \pm 7.51^{\mathrm{d}}$ & $29.97 \pm 2.26^{a}$ & $27.31 \pm 3.54^{b}$ & $0.14 \pm 0.11^{\circ}$ & $25.11 \pm 3.72^{b}$ \\
\hline $35 \mu \mathrm{W} \mathrm{cm} \mathrm{nm}^{-1}$ & $7.18 \pm 4.02^{\mathrm{a}}$ & $17.80 \pm 1.87^{\mathrm{b}}$ & $27.47 \pm 4.50^{b}$ & $0.23 \pm 0.08^{\mathrm{a}}$ & $27.20 \pm 7.63^{\mathrm{a}}$ \\
\hline $55 \mu \mathrm{W} \mathrm{cm} \mathrm{nm}^{-1}$ & $6.58 \pm 8.15^{b}$ & $14.85 \pm 1.30^{b}$ & $41.96 \pm 2.67^{\mathrm{a}}$ & $0.21 \pm 0.10^{b}$ & $27.37 \pm 6.41^{\mathrm{a}}$ \\
\hline $75 \mu \mathrm{W} \mathrm{cm} \mathrm{nm}^{-1}$ & $5.23 \pm 9.63^{\circ}$ & $19.08 \pm 2.98^{b}$ & $29.16 \pm 6.86^{b}$ & $0.15 \pm 0.00^{\circ}$ & $26.99 \pm 3.25^{\mathrm{a}}$ \\
\hline
\end{tabular}

Values are mean of three replicates \pm S.D. The letters $a, b, c$, and $d$ indicate that different letters in each column are significantly different at $p<0.05$ and vice versa 
Table 3: Effect of UV-B pre-treatment for 10 days on soluble protein, soluble sugar, proline, $\mathrm{H}_{2} \mathrm{O}_{2}$ and MDA contents in $P$. vulgaris leaves at seeding stage

\begin{tabular}{|c|c|c|c|c|c|}
\hline Treatments & $\begin{array}{l}\text { Soluble protein } \\
\text { (g | }\left.\right|^{-1} \text { f.wt.) }\end{array}$ & $\begin{array}{l}\text { Soluble sugar } \\
\text { (mg mg } \text { mrotein) }^{-1} \text { prote }\end{array}$ & $\begin{array}{l}\text { Proline } \\
\text { ( } \mu g^{-1} \text { f.wt.) }\end{array}$ & $\begin{array}{l}\mathrm{H}_{2} \mathrm{O}_{2} \\
\text { (mmol g-1 protein) }\end{array}$ & $\begin{array}{l}\text { MDA } \\
\text { (nmol mg-1 protein) }\end{array}$ \\
\hline Control & $4.3 \pm 0.02^{\mathrm{a}}$ & $6.33 \pm 0.10^{\text {bc }}$ & $35.24 \pm 2.65^{\mathrm{a}}$ & $31.38 \pm 1.06^{b}$ & $9.82 \pm 2.11^{b}$ \\
\hline $35 \mu \mathrm{W} \mathrm{cm}^{-2} \mathrm{~nm}^{-1}$ & $4.5 \pm 0.02^{\mathrm{a}}$ & $6.10 \pm 0.25^{\circ}$ & $38.27 \pm 1.05^{\mathrm{a}}$ & $29.29 \pm 0.58^{\circ}$ & $11.76 \pm 1.98^{b}$ \\
\hline $55 \mu \mathrm{W} \mathrm{cm} \mathrm{nm}^{-1}$ & $4.4 \pm 0.03^{\mathrm{a}}$ & $7.07 \pm 0.12^{\mathrm{a}}$ & $23.12 \pm 2.28^{b}$ & $31.62 \pm 0.30^{b}$ & $17.84 \pm 1.80^{\mathrm{a}}$ \\
\hline $75 \mu \mathrm{W} \mathrm{cm} \mathrm{nm}^{-1}$ & $4.6 \pm 0.03^{\mathrm{a}}$ & $4.72 \pm 0.14^{d}$ & $26.82 \pm 2.08^{b}$ & $45.37 \pm 1.59^{\mathrm{a}}$ & $20.27 \pm 4.11^{\mathrm{a}}$ \\
\hline
\end{tabular}

Values are mean of three replicates \pm S.D. The letters a, b, c, and d indicate that the different letters in each column are significantly different at $p<0.05$ and vice versa

Table 4: Effect of UV-B pre-treatment on caffeic acid, salviaflaside, rosmarinic acid, hyperoside, oleanolic acid and ursolic acid contents at maturefruiting stage in $P$. vulgaris ears

\begin{tabular}{lllllll}
\hline Treatments & $\begin{array}{l}\text { Rosmarinic } \\
\text { acid (\%) }\end{array}$ & $\begin{array}{l}\text { Caffeic } \\
\text { acid (\%) }\end{array}$ & $\begin{array}{l}\text { Salviaflaside } \\
(\%)\end{array}$ & $\begin{array}{l}\text { Hyperoside } \\
(\%)\end{array}$ & $\begin{array}{l}\text { Ursolic acid } \\
(\%)\end{array}$ & $\begin{array}{l}\text { Oleanolic acid } \\
(\%)\end{array}$ \\
\hline Control & $0.20 \pm 0.02^{\mathrm{c}}$ & $0.017 \pm 0.002^{\mathrm{b}}$ & $0.14 \pm 0.02^{\mathrm{c}}$ & $0.01 \pm 0.00^{\mathrm{b}}$ & $0.27 \pm 0.00^{\mathrm{a}}$ & $0.05 \pm 0.00^{\mathrm{a}}$ \\
$35 \mu \mathrm{W} \mathrm{cm} \mathrm{nm}^{-1}$ & $0.27 \pm 0.07^{\mathrm{a}}$ & $0.023 \pm 0.007^{\mathrm{a}}$ & $0.24 \pm 0.06^{\mathrm{a}}$ & $0.02 \pm 0.00^{\mathrm{a}}$ & $0.17 \pm 0.00^{\mathrm{b}}$ & $0.04 \pm 0.00^{\mathrm{b}}$ \\
$55 \mu \mathrm{W} \mathrm{cm}^{-2} \mathrm{~nm}^{-1}$ & $0.28 \pm 0.06^{\mathrm{a}}$ & $0.024 \pm 0.004^{\mathrm{a}}$ & $0.23 \pm 0.04^{\mathrm{a}}$ & $0.02 \pm 0.00^{\mathrm{a}}$ & $0.15 \pm 0.00^{\mathrm{c}}$ & $0.03 \pm 0.00^{\mathrm{c}}$ \\
$75 \mu \mathrm{W} \mathrm{cm}^{-2} \mathrm{~nm}^{-1}$ & $0.23 \pm 0.03^{\mathrm{b}}$ & $0.016 \pm 0.001^{\mathrm{b}}$ & $0.20 \pm 0.03^{\mathrm{b}}$ & $0.02 \pm 0.00^{\mathrm{a}}$ & $0.15 \pm 0.00^{\mathrm{c}}$ & $0.04 \pm 0.00^{\mathrm{b}}$ \\
\hline
\end{tabular}

Values are mean of three replicates \pm S.D. The letters $a, b, c$ and $d$ indicate that the different letters in each column are significantly different at $p<0.05$ and vice versa

Table 5: Primers used in RT-PCR analysis

\begin{tabular}{|c|c|}
\hline Gene & Primer sequence $\left(5^{\prime} \rightarrow 3^{\prime}\right)$ \\
\hline Phenylalanine ammonia lyase (PAL) & $\begin{array}{l}\text { F: TCCGTGCTTGTGTGTT TGTGCCTGTC } \\
\text { R: GGCTTCCTGAACTCCT CCACCATCCT }\end{array}$ \\
\hline Cinnamate acid 4-hydroxylase (C4H) & $\begin{array}{l}\text { F: GCGAACAACCCTGCCCAATGGAAGA } \\
\text { R: TGCCCTCCTTTCTCCGACGTACCAAT }\end{array}$ \\
\hline 4-coumarate-CoA ligase (4CL) & $\begin{array}{l}\text { F: CCACAAGAGCCTCATCACCAGCATCG } \\
\text { R: TGAGCGAGCAGAGCAGGACGGAAT }\end{array}$ \\
\hline Chalcone synthase (CHS) & $\begin{array}{l}\text { F: AACAGCGAGCATAAGACCGACCTCAA } \\
\text { R: CGCCGTGATGTTTGGGTTCTCCTTC }\end{array}$ \\
\hline Chalcone isomerase $(\mathrm{CHI})$ & $\begin{array}{l}\text { F: CTTCACTCAGTCACCTGCTGGCTCAC } \\
\text { R: AACTCTGCCTTGCCGTGGGAGACA }\end{array}$ \\
\hline Rosmarinic acid synthetase (RAS) & $\begin{array}{l}\text { F: CGTC TCCG CTCT CCAC TTCA TCAA CA } \\
\text { R: GGAGT AGGC GATC TCGG TGTC TTGG }\end{array}$ \\
\hline$\beta$-actin & $\begin{array}{l}\text { F: TGGTCGGAATGGGACAGAAG } \\
\text { R: CTCAGTCAGGAGAACAGGGT }\end{array}$ \\
\hline
\end{tabular}

Remark: accession numbers of genes: PAL (KJ010815.1), C4H (KJ010816.1), 4CL (KJ010814.1), CHS (KF255834.1), CHI (MH447677.1), RAS (KM575933.1)

different from the results un-irradiated treatment, except for slight but insignificant $(p<0.05)$ decrease in caffeic acid under higher UV-B. The contents of oleanolic acid and ursolic acid were significantly $(p<0.05)$ decreased when plants were subjected to UV-B radiation as compared to un-irradiated treatment (Table 4). The results of analysis of $C 4 H, P A L, 4 C L, C H S, R A S$ and $C H I$ gene expression are shown in Fig. 1. Compared with unirradiated plants, the expression of six genes in UV-B-treated spicas sharply increased and reached peak under lower UV-B treatment. UV-B irradiation resulted in significant $(p<0.05)$ accumulation of $P A L, C H S$ and $C H I$ transcripts at seedling stage. The expression levels of $\mathrm{C} 4 \mathrm{H}$ and $\mathrm{RAS}$ were significantly $(p<0.05)$ increased under lower UV-B treatment, but under intermediate and higher UV-B treatment, there was little difference compared with the control plants. $4 C L$ transcript abundance significantly $(p<0.05)$ increased at lower and intermediate UV-B treatments and decreased under higher UV-B treatment compared with the control treatment. 


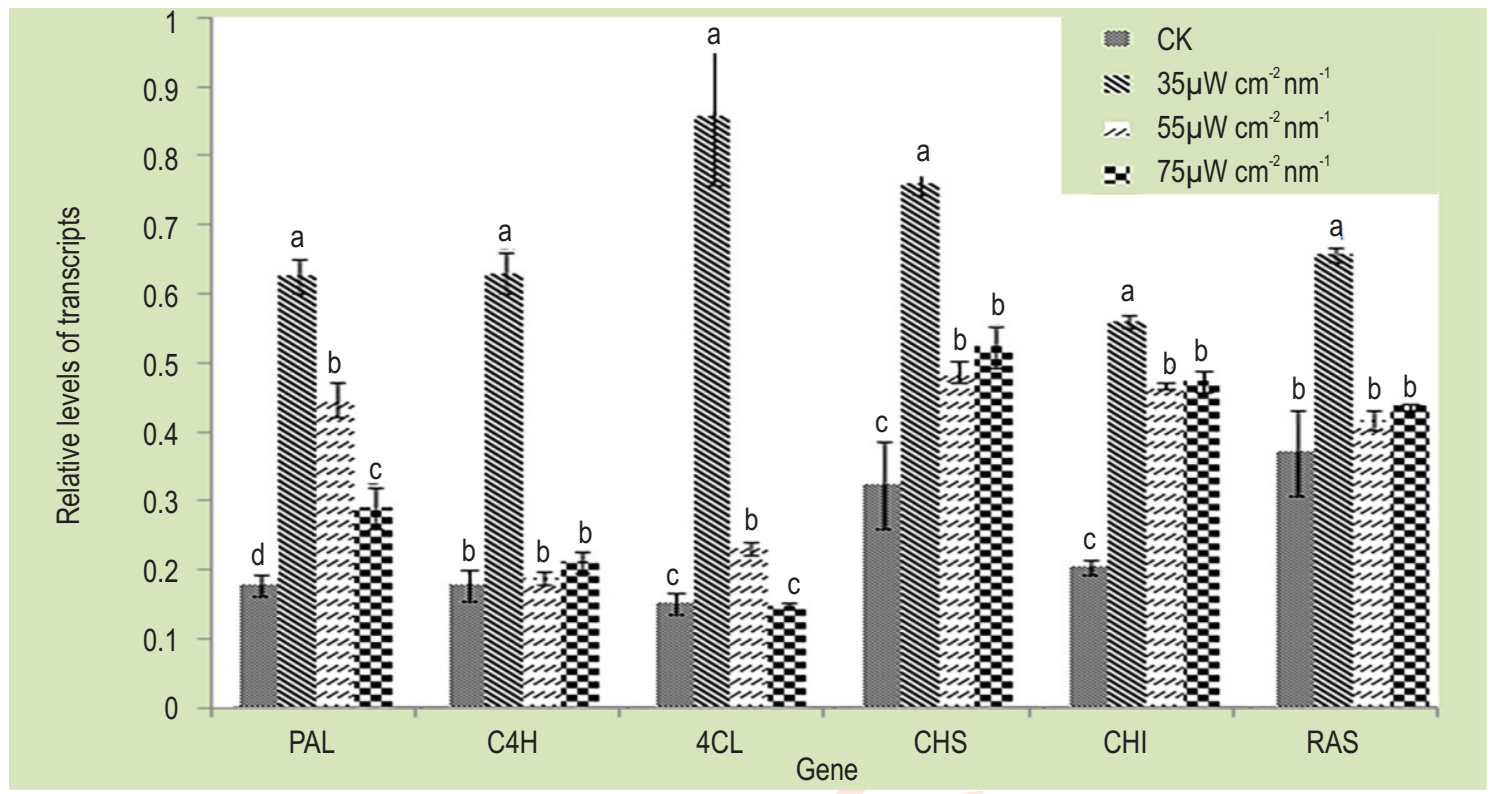

Fig.1: Expression levels of PAL, 4CL, C4H, CHI, CHS and RAS genes at seedling stage of $P$. vulgaris under UV-B and control treatments. Values are mean of three replicates \pm S.D. The letters $a, b, c$, and d indicate that different letters above same pattern indicate a significant difference at $p<0.05$.

The present study showed that anthocyanin contents increased under UV-B radiation (Table 2). This study revealed that UV-B radiation stimulates $P$. vulgaris leaves to produce anthocyanins, which is similar to the findings of previous studies (Kataria et al., 2014). Anthocyanin mainly occurs in the epidermal cells of leaves or other plant parts (Feild et al., 2001) and modulates damage by decreasing the permeation UVB (WinkelSherley, 2002). Thus, anthocyanin content in $P$. vulgaris increased under UV-B irradiation. In contrast, UV absorber compounds did not show significant changes under different intensities of UV-B radiation, consistent with previous studies (Shi et al., 2010). A reasonable explanation for this finding is that the mature leaves of $P$. vulgaris already have high contents of UV-absorbing substances in the epidermis that prevents possible damage by UV-B radiation and maintain a stable level of UV-absorbing substances. This relative stability of UV-B-absorbing substances may also be related to the longer metabolic period in mature leaves.

Plants activate non-enzymatic and antioxidant enzyme system to quench ROS induced by UV-B radiation (Barta et al., 2004). In this work, the activities of POD, APX and SOD and GSH content all increased under UV-B radiation, but CAT activities were significantly decreased under diferent UV-B radiation intensities; these results are in confirmation with the previous reports of (Rai et al., 2011). Enhanced SOD, POD and APX level increases the oxygen radical scavenging capacity of plants and maintains cellular membrane integrity and sub-cellular structures (InostrozaBlancheteau et al., 2016). When GSH content increases, UV-B radiation injury is alleviated (Yan et al., 2016). In P. vulgaris leaves, CAT activities significantly reduced under varied UV-B radiation intensities of UV-B causes ROS and lipid peroxidation damage to plant cells, reducing their ability to respond to oxidative stress (Gao et al., 2008). On the other hand, P. vulgaris produces antioxidants such as glutathione, ascorbate and a-tocopherol to offset the negative effects of UV-B exposure (Jain et al., 2004). Under UV-B stress, the contents of soluble sugar and soluble protein in $P$. vulgaris leaves increased, similar to previous results. Soluble sugars and proteins are osmotic regulatory substances involved in adaptation to UV-B stress through osmotic regulation (Wu et al., 2016). Interestingly, the soluble sugar contents of $P$. vulgaris leaves were significantly reduced due to higher UV-B stress, similar to previous results. Hydrolase activity was inhibited under UV-B stress, thereby reducing the hydrolysis rate in the conversion of macromolecular components into small molecules like soluble sugars. Additionally due to oxidation stress inducing more ROS under higher UV-B levels, reducing sugars might be oxidized, thus decreasing their levels (Jiao et al., 2015). Proline accumulation under UV-B stress presents great protective potential against ROS induced by oxidative stress in plant cells (Kumar and Bhardwaj, 2019). In contrast to the increased proline content of $P$. vulgaris leaves under lower UV-B irradiation, a decrease was observed under both intermediate and higher UV-B treatments (Katerova et al., 2009). reported a similar trend in proline contents in pea under UV-B treatments. MDA is used as an indicator of oxidative stress (Chen et al., 2019), and UV-B stress has been found to increase MDA content in previous studies, indicating oxidative damage (Yan et al., 2016). 
Rosmarinic acid is the main active ingredient in $P$. vulgaris spicas and is the component employed for quality control in the spicas of $P$. vulgaris in the Chinese Pharmacopoeia (2015). In this study, the rosmarinic acid content under different UV-B intensity radiation treatments was significantly increased compared to the control group, and similar results were reported Zhang et al. (2017). Some studies have shown that rosmarinic acid presents a superior ROS-scavenging ability and is a photoprotective agent, and suppress $U V$ radiation-induced ROS production in the cells of human skin in pharmacological studies (Sánchez-Campillo et al., 2009). These findings provide enough evidence to prove that the increase rosmarinic acid in $P$. vulgaris spicas can eliminate ROS induced by UV-B stress. Hyperoside and caffeic acid are the main active ingredients in the spicas of $P$. vulgaris (Chen et al., 2013).

It has been observed that hyperoside and caffeic acid are more abundant in plants coping with abiotic stress of high UV-B radiation (Cirak et al., 2017). Previous studies have indicated that hyperoside and caffeic acid are effective ROS scavengers that can protect the phospholipid bilayer of cell membrane from UV-B irradiation (Camas et al., 2014). Thus, the increase in hyperoside and caffeic acid contents found in $P$. vulgaris under pre-treatment with UV-B may help to remove ROS in the cells of $P$. vulgaris. Salviaflaside is the main phenolic glycoside found in $P$. vulgaris. In our study, pre-treatment with UV-B radiation significantly increased salviaflaside contents. It was found that the expression of key genes related to phenolic acid biosynthesis (e.g., PAL, $4 C L, C 4 H, R A S, C H S$ and $C H I$ ) increased in $P$. vulgaris leaves under UV-B stress, which may be the reason for increased salviaflaside content found in $P$. vulgaris under pre-treatment with UV-B radiation. Oleanolic acid and ursolic acid are commonly found in the spicas of $P$. vulgaris (Bai et al., 2016). This study reveals that the contents of oleanolic acid and ursolic acid significantly decreased under pre-treatment with UV-B radiation, similar to the results previously obtained by others (Ambasht and Agrawal, 1998). Another study indicated that the expression of triterpenoid synthesis genes was not affected by UV-B irradiation (Zhao et al., 2013). This may be the reason for decreased oleanolic acid and ursolic acid contents observed in $P$. vulgaris under pre-treatment with UV-B radiation.

In this study, when $P$. vulgaris was pre-treated with UV-B radiation, six kinds of critical phenylpropanoid pathway enzymes (e.g., PAL, 4CL, C4H, CHI, CHS and RAS) showed higher transcript accumulation. Increased expression of genes encoding enzymes involved in the phenylpropanoid pathway, especially $P A L$, is induced by UV-B radiation and plays a key role in the first and most important step of the phenylpropanoid pathway, which results in increases in individual phenolic acids (Yu et al., 2015). CHS is the first flavonoid enzyme in the flavonoid pathway (Samuelian et al., 2009). This study indicated that UV-B induced significant accumulation of $\mathrm{CHS}$ transcripts, which explains the observed increase in the contents of individual flavonoids. In conclusion, this study demonstrated that UV-B pre-treatment in the seedling stage before transplantation to the field is effective for inducing phenolic acid and flavonoid accumulation in the mature fruiting stage of $P$. vulgaris ears. However, further studies should be carried out to clarify the multiple metabolic pathways of UV-B radiation regulating $P$. vulgaris.

\section{Acknowledgments}

This study was funded by programs of the National Nature Science Foundation of China (31500263, 30772730 and 81072986), Basic Research Program of Sichuan Province of China (2019YJ0368), Scientific Research Foundation of Chengdu Medical College (CYH19-35) and the Sichuan Province Undergraduates Innovating Experimentation Project (201813705027).

\section{References}

Agrawal, S.B. and S. Mishra: Effects of supplemental ultraviolet-B and cadmium on growth, antioxidants and yield of Pisum sativum L. Ecotoxicol. Environ. Saf., 72, 610-618 (2009).

Ambasht, N.K. and M. Agrawal: Influence of supplemental UV-B radiation on photosynthetic characteristics of rice plants. Photosynthetica, 34, 401-408 (1998).

Bai, Y.B., B.H. Xia, W.J. Xie, Y.M. Zhou, J.C.Xie, H.Q. Li, D.F. Liao, L.M. Lin and C. Li: Phytochemistry and pharmacological activities of the genus Prunella. Food Chem., 204, 483-496 (2016).

Barta, C., T. Kálai, K. Hideg, I. Vass and É. Hideg: Differences in the ROS-generating efficacy of various ultraviolet wavelengths in detached spinach leaves. Funct. Plant Biol., 31, $23-28$ (2004).

Board of Pharmacopoeia of P.R. China: Pharmacopoeia of the People's Republic of China. Beijing: China Medico-Pharmaceutical Science \& Technology Puhlishig House, p. 280 (2015).

Caldwell, M.M., C.L. Ballaré, J.F. Bornman, S.D. Flint, L.O. Björn, A.H. Teramura, G. Kulandaivelu and M. Tevini: Terrestrial ecosystems, increased solar ultraviolet radiation and interactions with other climatic change factors. Photoch. Photobio. Sci., 2, 29-38 (2003).

Camas, N., J. Radusiene, L. Ivanauskas, V. Jakstas and C. Cirak: Altitudinal changes in the content of bioactive substances in Hypericum orientale and Hypericum pallens. Acta Physiol. Plant., 36, 675-686 (2014).

Chen, Y.H., M.M. Yu, Z.B. Zhu, L.X. Zhang and Q.S. Guo: Optimisation of potassium chloride nutrition for proper growth, physiological development and bioactive component production in Prunella vulgaris L. PLoS One, 8, e66259 (2013).

Chen, Y.H., X.R. Zhang, Q.S. Guo, L.P. Cao, Q. Qin, C. Li, M. Zhao and W.M. Wang: Plant morphology, physiological characteristics, accumulation of secondary metabolites and antioxidant activities of Prunella vulgaris L. under UV solar exclusion. Biol. Res., 52, 17 (2019).

Chen, Y.H., X.R. Zhang, Q.S. Guo, L. Liu, C. Li, L.P. Cao, Q. Qin, M. Zhao and W.M. Wang: Effects of UV-B radiation on the contents of bioactive components and the antioxidant activity of Prunella vulgaris L. spica during development. Molecules, 23, 989 (2018).

Cheung, H.Y. and Q.F. Zhang: Enhanced analysis of triterpenes, flavonoids and phenolic compounds in Prunella vulgaris $\mathrm{L}$. by capillary zone electrophoresis with the addition of running buffer modifiers. J. Chromatogr. A., 1213, 231-238 (2008).

Cirak, C., J. Radusiene, V. Jakstas, L. Ivanauskas, F. Seyis and F. Yayla: Altitudinal changes in secondary metabolite contents of Hypericum androsaemum and Hypericum polyphyllum. Biochem. Syst. Ecol., 70, 108-115(2017).

Dolzhenko, Y., C.M. Bertea, A. Occhipinti, S. Bossi and M.E. Maffei:UV-B 
modulates the interplay between terpenoids and flavonoids in peppermint (Mentha × piperita L.). J. Photoch. Photobio. B., 100, 67-75(2010).

Eichholz, I., S. Rohn, A. Gamm, N. Beesk, W.B. Herppich, L.W. Kroh, C. Ulrichs and S. Huyskens-Keil: UV-B-mediated flavonoid synthesis in white asparagus (Asparagus officinalis L.). Food. Res. Int., 48, 196-201 (2012).

Fazal, H., B.H. Abbasi, N. Ahmad, S.S. Ali, F. Akbar and F. Kanwal: Correlation of different spectral lights with biomass accumulation and production of antioxidant secondary metabolites in callus cultures of medicinally important Prunella vulgaris $\mathrm{L}$. J. Photoch. Photobio. B, 159, 1-7 (2016).

Feild, T.S., D.W. Lee and N.M. Holbrook: Why leaves turn red in autumn. The role of anthocyanins in senescing leaves of red-osier dogwood. Plant Physiol., 127, 566-574 (2001).

Gao, Q. and L.X. Zhang: Ultraviolet-B-induced oxidative stress and antioxidant defense system responses in ascorbate-deficient vtc1 mutants of Arabidopsis thaliana. J. Plant Physiol., 165, 138-148 (2008).

Inostroza-Blancheteau, C., P. Acevedo, R. Loyola, P. Arce-Johnson, M. Alberdi and M. Reyes-Diaz: Short-term UV-B radiation affects photosynthetic performance and antioxidant gene expression in highbush blueberry leaves. Plant Physiol. Bioch., 107, 301-309 (2016).

Jain K., S. Kataria and K.N. Guruprasad: Effect of UV-B radiation on antioxidant enzymes and its modulation by benzoquinone and a-tocopherol in cucumber cotyledons, Curr. Sci., 87, 87-90 (2004).

Jiao, J., Q.Y. Gai, W. Wang, M. Luo, C.B. Gu, Y.J. Fu and W. Ma: Ultraviolet radiation-elicited enhancement of isoflavonoid accumulation, biosynthetic gene expression, and antioxidant activity in Astragalus membranaceus hairy root cultures. J. Agr. Food. Chem., 63, 8216-8224 (2015).

Kataria, S., A. Jajoo and K.N. Guruprasad: Impact of increasing ultraviolet-B (UV-B) radiation on photosynthetic processes. J. Photoch. Photobio. B., 137, 55-66 (2014).

Katerova Z., S. Ivanov and S. Mapelli: Phenols, proline and lowmolecular thiol levels in pea (Pisum sativum) plants respond differently toward prolonged exposure to ultraviolet-B and ultraviolet-C radiations. Acta Physiol. Plant., 31, 111-117 (2009).

Kim, Y. B., Y. Shin, P. A. Tuan, X. Li, Y. Park, N. Park and S. U. Park: Molecular cloning and characterization of genes involved in rosmarinic acid biosynthesis from Prunella vulgaris. Biol. Pharm. Bull., 37, 1221-1227 (2014).

Kumar, G. and M. Bhardwaj: Induced genetic variations in Cuminum cyminum through supplemental UV-B radiation. J. Environ. Biol., 40, 342-348 (2019).

Liu, B., X.B. Liu, Y.S. Li and S.J. Herbert: Effects of enhanced UV-B radiation on seed growth characteristics and yield components in soybean. Field Crop. Res., 154, 158-163 (2013).
Rai R., R.P. Meena, S.S. Smita, A. Shukla, S.K. Rai and S. Pandey-Rai: UV-B and UV-C pre-treatments induce physiological changes and artemisinin biosynthesis in Artemisia annua L. - An antimalarial plant. J. Photochem. Photobiol. B., 105, 216-225 (2011).

Samuelian, S.K., C. Camps, C. Kappel, E.P. Simova, S. Delrot and V.M. Colova: Differential screening of overexpressed genes involved in flavonoid biosynthesis in North American native grapes: 'Noble muscadinia var. and Cynthiana aestivalis var. Plant Sci., 177, 211 221 (2009).

Sánchez-Campillo, M., J.A. Gabaldon, J. Castillo, O. Benavente-García, M.J. Del Baño, M. Alcaraz, V. Vicente, N. Alvarez and J.A. Lozano: Rosmarinic acid, a photo-protective agent against UV and other ionizing radiations. Food Chem. Toxicol., 2, 386-392 (2009).

Shi, S.B., Y.X. Shang, P.J. Zhu and D.G. Zhang: Effect of enhanced UV-B radiation on photosynthesis and photosynthetic pigments in Alpine plants Saussurea superba. Acta Agrestia Sin., 18, 607-614 (2010).

Singh, S., R. Kumari, M. Agrawal and S.B. Agrawal: Growth, yield and tuber quality of Solanum tuberosum L. under supplemental ultraviolet-B radiation at different NPK levels. Plant Biol., 13, 508516 (2011).

Tossi, V., M. Amenta, L. Lamattina and R. Cassia: Nitric oxide enhances plant ultraviolet-B protection up-regulating gene expression of the phenylpropanoid biosynthetic pathway. Plant Cell Environ., 34, 909-921 (2011).

Wang, Y.X., J.B. Yin, Q.S. Guo and Y.H. Xiao: Dynamic change of active component content in different parts of Prunella vulgaris. China J. Chin. Materia Med., 36, 741-745 (2011).

Winkel-Sherley, B.: Biosynthesis of flavonoids and effects of stress. Curr. Opin. Plant Biol., 5, 218-223 (2002).

Wu, X.L., J. Yuan, A.X. Luo, Y. Chen and Y.J. Fan: Drought stress and rewatering increase secondary metabolites and enzyme activity in Dendrobium moniliforme. Ind. Crop. Prod., 94, 385-393 (2016).

Yan, F., Y. Liu, H. Sheng, Y. Wang, H. Kang and J. Zeng: Salicylic acid and nitric oxide increase photosynthesis and antioxidant defense in wheat under UV-B stress. Biol. Plantarum, 60, 686-694 (2016).

Yu, X., L. Jiang, H. Wang, P. Jin and Y. Zheng: Effect of UV-C treatment on quality and phenylpropanoid metabolism of postharvest Chinese bayberry fruit. Food Sci., 12, 255-259 (2015).

Zhang, W.J. and L.O. Bjorn: The effect of ultraviolet radiation on the accumulation of medicinal compounds in plants. Fitoterapia, $\mathbf{8 0}$, 207-218 (2009).

Zhang, X.R., Y.H. Chen, Q.S. Guo, W.M. Wang, L. Liu, J. Fan, L.P. Cao and C. Li: Short-term UV-B radiation effects on morphology, physiological traits and accumulation of bioactive compounds in Prunella vulgaris L. J. Plant Interact., 12, 348-354 (2017).

Zhao, Z.J., Y.G. Song, Y.L. Liu, M. Qiao, X.L. Zhai and F.N. Xiang: The effect of elicitors on oleanolic acid accumulation and expression of triterpenoid synthesis genes in Gentiana straminea. Biol. Plantarum, 57, 139-143 (2013). 